\title{
HUBUNGAN PARITAS DENGAN KEJADIAN PERDARAHAN PADA IBU POST PARTUM DI BPS NY. N DI DESA KLAGEN SERUT KECAMATAN JIWAN
}

\author{
MADIUN \\ Etika Desi Yogi ${ }^{1)}$, Sinta Ayu Setiawan, ${ }^{2)}$ Sri Dwi Hastuti ${ }^{3)}$ \\ Akbid Harapan Mulya Ponorogo ${ }^{1) 2) 3)}$ \\ Email: deassyyogiyanaetika@yahoo.co.id ${ }^{1)}$
}

\begin{abstract}
Maternal Mortality Rate in East Java 2011 were 101.40 per 100,000 births. The of incidence of maternal mortality in East Java in 2011 was caused by direct obstetric or the bleeding. Factors that lead to postpartum hemorrhage include the presence of uterine atony, retained placenta, lacerations of the birth canal and the blood clotting factor, whereas postpartum hemorrhage predisposing factors that include hydramnios, gemeli, parity and age. Data from the Madiun County Health Department in 2011 found bleeding number 230 of 12698 maternal. At BPS Ny. Niniek Soelasminingsih, S.ST in 2011 from 58 deliveries got the bleeding as much as 6 patients deliver within 24 hours post partum, 2 people tear the multiparous born 4 cases with uterine atony.

This study aims to determine the relationship of parity with the incidence of postpartum bleeding. Type of study is the correlation with the analytic case-control approach. Collecting data using retrospective data. Samples from this study were all mothers giving birth at BPS Ny Niniek Soelasminingsih, S.ST from the medical records of a total of 61 maternal. The study was conducted in November 2012, the data were analyzed using Chi Square statistical test with a significance level set at $p \leq 0.05$.

The results showed that the number of women who experience bleeding as many as 12 people, most bleeding is multiparitas mothers by 5 people. Having analyzed by chi-square statistical test results showed no association between parity and incidence of postpartum hemorrhage in BPS Ny. Niniek Soelasminingsih S.ST 0.008 with $p$ value $\leq 0.05$ in other words Ha received.

Recommended that the delivery assistance by personnel who are competent so that the incidence of postpartum hemorrhage can be treated as good as possible so that the maternal mortality rate in Indonesia could be on tap as well as early detection of high risk pregnant women and maternity over increased.
\end{abstract}

\section{PENDAHULUAN}

Perdarahan post partum adalah perdarahan post partum dini primer (Early Post Partum) yang terjadi setelah melahirkan. Perdarahan post partum sekunder (Late Post Partum) terjadi setelah 24 jam biasanya antara hari ke 5 sampai hari ke 15 post partum (Mochtar 1998:298).

Berdasarkan Profil Kesehatan Jatim tahun 2011 AKI di Propinsi Jawa Timur pada lima tahun terakhir, dari tahun 20072011menunjukkan kecenderungan yang meningkat. Tahun 2011 AKI di Jawa Timur 101.40 per $100.000 \mathrm{KH}$. Kejadian kematian ibu di Jawa Timur tahun 2011 paling banyak adalah karena penyebab obstetrik langsung yaitu perdarahan $28 \%$, eklampsia $24 \%$, dan infeksi $11 \%$ serta
37\% disebabkan oleh sebab tidak langsung misalnya kekurangan energi kronis, anemia, sakit jantung, dan diabetes melitus (Depkes RI, 2008).

Data dari kantor Dinas Kesehatan Kabupaten Madiun tahun 2011 AKI 85,63 per $100.000 \mathrm{KH}$, didapatkan jumlah perdarahan 230 dari 12.698 ibu bersalin. Di BPS Ny. Niniek Soelasminingsih, S.ST pada tahun 2011 dari 58 persalinan didapatkan perdarahan sebanyak 6 pasien melahirkan dalam 24 jam post partum, 2 orang robekan jalan lahir 4 kasus multipara dengan atonia uteri.

Faktor yang menyebabkan terjadinya perdarahan postpartum diantaranya adalah adanya atonia uteri, retensio plasenta, laserasi jalan lahir dan faktor bekuan darah, sedangkan faktor predisposisi 
terjadinya perdarahan postpartum yang antara lain adalah hidramnion, gemeli, paritas dan usia (Prawirohadjo, 2008:524). Paritas adalah seorang wanita yang pernah melahirkan bayi yang dapat hidup (viable) (Wiknjosastro, 2005:180). Uterus yang melahirkan banyak anak cenderung bekerja tidak efisien dalam semua kala persalinan. Karena ibu sering melahirkan maka kemungkinan ditemui keadaan kesehatan terganggu, anemia, kurang gizi, kekendoran dinding perut tampak perut ibu menggantung) kekendoran dinding rahim, sedangkan bahaya yang dapat terjadi kelainan letak, robekan rahim pada kelainan letak lintang, persalinan lama dan perdarahan pasca persalinan.

Kematian ibu dan perinatal tersebut dapat dihindarkan dengan meningkatkan pelayanan kesehatan terutama meningkatkan upaya pengawasan ibu hamil sehingga dapat mendeteksi lebih dini keadaan-keadaan yang mengandung resiko kehamilan dan persalinan baik bagi ibu maupun janin. Dengan demikian dapat diharapkan meningkatkan status kesehatan ibu dan bayi sehingga dapat mewujudkan salah satu program pembangunan nasional yaitu meningkatkan kualitas Sumber Daya Manusia (SDM) Indonesia

Berdasarkan fenomena di atas peneliti ingin mengetahui apakah terjadi hubungan antara paritas dengan terjadinya perdarahan di BPS Ny.Niniek Soelasminingsih,S.ST di Desa Klagen Serut Kecamatan Jiwan Kabupaten Madiun dengan demikian nantinya dapat diambil langkah-langkah yang tepat untuk pencegahannya.

\section{METODE PENELITIAN}

Jenis penelitian ini menggunakan metode analitik korelasi, yaitu suatu penelitian dengan mengkaji hubungan antara variabel. Dalam penelitian ini akan dilakukan analisis hubungan antara paritas dengan perdarahan post partum. Sedangkan pada rancangan penelitian ini menggunakan pendekatan "case control".

Rancangan penelitian case control yaitu Suatu penelitian (survey) analitik yang menyangkut bagaimana faktor resiko dipelajari dengan menggunakan pendekatan "retrospektive"

Populasi dalam penelitian ini adalah semua ibu bersalin di BPS Ny Niniek Soelasminingsih, S.ST berdasarkan buku register.

Teknik yang digunakan "total sampel" yaitu teknik penetapan sampel dengan cara mengambil seluruh populasi sebagai sampel

Variabel independent dalam penelitian ini adalah paritas. Variabel terikat dalam penelitian ini adalah perdarahan post partum.

Analisa data untuk mengetahui hubungan paritas dengan perdarahan post partum menggunakan uji statistik chisquare dengan bantuan SPSS statistic18 dengan taraf signifikasi $(0,05)$.

\section{HASIL PENELITIAN}

Tabel 1

Tabulasi data ibu bersalin berdasarkan paritas

\begin{tabular}{llcc}
\multicolumn{4}{c}{ paritas } \\
\hline No & Paritas & f & \% \\
\hline 1. & Primipara & 26 & $42,6 \%$ \\
\hline 2. & Multipara & 29 & $47,6 \%$ \\
\hline 3 & $\begin{array}{l}\text { Grande } \\
\text { multipara }\end{array}$ & 6 & $9,8 \%$ \\
\hline \multicolumn{2}{c}{ Total } & 61 & 100 \\
\hline
\end{tabular}

Dari tabel diatas menunjukkan yang banyak bersalin pada periode Januari sampai Juni 2012 adalah ibu yang memiliki anak 2-4 (multipara) 29 orang $(47,6 \%)$, sedangkan ibu yang memiliki anak 1 (primipara) sebanyak 26 orang $(42,6 \%)$, ibu yang mempunyai anak $\geq 5$ sebanyak 6 orang $(9,8 \%)$.

Tabel 2

Tabulasi data kejadian perdarahan ibu Post Partum

\begin{tabular}{clcc}
\hline No & $\begin{array}{l}\text { Kejadian } \\
\text { perdarahan }\end{array}$ & f & \% \\
\hline 1. & Normal & 49 & $80,3 \%$ \\
\hline 2. & Perdarahan & 12 & $19,7 \%$ \\
\hline & Total & 61 & $100 \%$ \\
\hline
\end{tabular}

Dari tabel diatas menunjukkan bahwa ibu yang mengalami perdarahan 12 orang $(19,7 \%)$ sedangkan ibu yang tidak mengalami perdarahan sebanyak 49 orang $(80,3 \%)$.

Tabel 3

Tabulasi data penyebab perdarahan pada ibu post partum 


\begin{tabular}{llcc}
\hline No & $\begin{array}{l}\text { Penyebab } \\
\text { Perdarahan }\end{array}$ & f & $\%$ \\
\hline $\mathbf{1}$ & $\begin{array}{l}\text { Robekan jalan } \\
\text { lahir }\end{array}$ & 2 & $16,7 \%$ \\
\hline $\mathbf{2}$ & Atonia Uteri & 6 & $50 \%$ \\
\hline $\mathbf{3}$ & Retensio & 4 & $33,3 \%$ \\
\hline & Jumlah & 12 & $100 \%$ \\
\hline
\end{tabular}

Berdasarkan tabel 5.4 penyebab perdararahan terbanyak yaitu karena adanya atonia uteri yaitu 6 orang $(50 \%)$, karena robekan jalan lahir 2 orang $(16,7 \%)$ dan karena retensio plasenta sebanyak 4 orang $(33,3 \%)$.

\section{Tabel 4}

Tabulasi silang Paritas dengan kejadian perdarahan post partum

\begin{tabular}{|c|c|c|c|c|c|}
\hline \multirow[t]{2}{*}{ Paritas } & $\begin{array}{l}\text { tidak } \\
\text { perdarahan }\end{array}$ & \multicolumn{2}{|c|}{ Perdarahan } & \multicolumn{2}{|c|}{ Jumlah } \\
\hline & f $\%$ & $\mathrm{f}$ & $\%$ & $\mathrm{f}$ & $\%$ \\
\hline Primi & $\begin{array}{ll}23 & 46,9\end{array}$ & 3 & 25 & 26 & $\begin{array}{c}42, \\
6\end{array}$ \\
\hline Multi & $24 \quad 49$ & 5 & 41.7 & 29 & $\begin{array}{c}47, \\
6\end{array}$ \\
\hline Grande & 4,1 & 4 & 33,3 & 6 & 9,8 \\
\hline Total & $49 \quad 100$ & 12 & 100 & 61 & 100 \\
\hline $\begin{array}{l}\quad \text { Be } \\
\text { primip } \\
\text { sebany } \\
\text { menga } \\
(46,9 \% \\
\text { perdar } \\
\text { yang } \\
\text { sebany } \\
\text { multip } \\
\text { sebany } \\
\text { yang } \\
\text { sebany }\end{array}$ & $\begin{array}{l}\text { dasarkan } \\
\text { ra yang } \\
\text { k } 3 \text { 0rans } \\
\text { ami perdas } \\
\text {, Ibu mu } \\
\text { han seban } \\
\text { tidak } \\
\text { k } 24 \text { ora } \\
\text { ra yang } \\
\text { t } 4 \text { ora } \\
\text { tidak } \\
\text { k } 2 \text { orang }\end{array}$ & $\begin{array}{l}\text { en } \\
25 \\
\text { lan } \\
\text { par } \\
\text { k } 5 \\
\text { nga } \\
\text { (4 } \\
\text { eng } \\
\text { (? } \\
\text { nga }\end{array}$ & $\begin{array}{l}\text { lami } \\
\text { dan } \\
\text { ebany } \\
\text { yang } \\
\text { rang } \\
\text { imi } \\
9 \% \text { ), } \\
\text { lami } \\
, 3 \%) \\
\text { mi }\end{array}$ & $\begin{array}{l}\text { per } \\
\text { ibu } \\
\text { per } \\
\text { sed } \\
\text { per }\end{array}$ & $\begin{array}{l}\text { ora } \\
\text { sala } \\
\text { o) d } \\
\text { arah } \\
\text { arah } \\
\text { arah } \\
\text { arah }\end{array}$ \\
\hline
\end{tabular}

\section{PEMBAHASAN}

\section{Paritas}

Dapat diketahui bahwa jumlah ibu bersalin di BPS Ny Niniek Soelasminingsih di Desa Klagen Serut Kecamatan Jiwan yang paling banyak hampir setengahnya adalah ibu multipara yaitu 29 orang $(47,6 \%)$, hampir setengahnya lagi ibu primipara yaitu 26 orang $(47,6 \%)$ dan sebagian kecil ibu grandemultipara yaitu 6 orang $(9,8 \%)$.

Menurut Wiknjosastro, (2002:180) multiparitas adalah wanita yang telah melahirkan anak lebih dari 1 sampai batas anak hidup 4. Semakin banyak jumlah anak yang dilahirkan maka komplikasi yang akan dialami juga akan meningkat. Seorang wanita yang telah mengalami kehamilan sebanyak 6 kali atau lebih, lebih mungkin mengalami Kontraksi yang lemah pada saat persalinan, perdarahan setelah persalinan (karena otot rahimnya lemah), Lebih tinggi paritas, lebih tinggi kematian maternal (Wiknjosastro, 2002:23).

Paritas mempunyai andil besar terhadap kemungkinan terjadinya perdarahan post partum. Sehingga ibu yang telah lebih dari 4 kali melahirkan dianjurkan untuk tidak mempunyai keturunan lagi. Hal ini untuk dapat menghindari terjadinya resiko perdarahan pada saat dan sesudah persalinan serta ikut membantu menurunkan AKI (Angka Kematian Ibu) di Indonesia yang masih tinggi yang disebabkan diantaranya karena adanya perdarahan post partum.

2. Kejadian Perdarahan Post Partum

Didapatkan ibu yang mengalami perdarahan sebanyak 12 orang $19,78 \%$ dan yang tidak mengalami perdarahan sebanyak 49 orang $(80,3 \%)$. Berdasarkan tabel 5.4 penyebab perdarahan 6 orang $(50 \%)$ karena atonia uteri, karena robekan jalan lahir sebanyak 2 orang (16,7\%), dan karena retensio plasenta 4 orang $(33,3 \%)$.

Menurut Wiknjosastro, (2008:523) perdarahan post partum adalah kehilangan $500 \mathrm{ml}$ darah atau lebih setelah kelahiran pervaginam. perdarahan post partum merupakan penyebab utama kematian ibu lebih dari $50 \%$ dari jumlah kematian ibu terjadi dalam 24 jam setelah melahirkan karena terlalu banyak mengeluarkan darah.

Faktor predisposisi perdarahan post partum adalah anemia, overdistensi uterus (gemelli, hidramnion, janin besar >4000 gram), paritas, jarak persalinan, solusio plasenta, malnutrisi, dan kelahiran sesaria (Wiknjosastro, 2002:448). 
Menurut Manuaba, (1998:653) Perdarahan post partum diklasifikasikan menjadi 2 yaitu perdarahan post partum primer (Early Post Partum Hemorrhage) terjadi dalam 24 jam pertama setelah melahirkan.

Penyebab utamanya adalah atonia uteri, retensio plasenta, sisa plasenta, laserasi jalan lahir. Sedangkan perdarahan post partum sekunder (late post partum hemorrhage) terjadi setelah 24 jam pertama post partum. Paling umum merupakan akibat sub involusi uterus, jaringan plasenta tertahan, terbukanya luka episiotomi atau SC, dan infeksi.

Setelah persalinan sampai 2 jam perlu pengawasan yang lebih intensif karena perdarahan bisa terjadi sebelum 24 jam atau setelah 24 jam. Pengawasan pada 1 jam pertama setiap 15 menit, dan pada jam ke 2 setiap 30 menit. Pengawasan meliputi tandatanda vital, kontraksi uterus, kandung kencing, perdarahan, sehingga jika terjadi perdarahan atau komplikasi lainnya dapat segera tertangani dengan baik.

3. Hubungan Paritas Pada Ibu Bersalin Dengan Perdarahan Post Partum

Berdasarkan tabulasi silang paritas dengan kejadian perdarahan pada ibu post partum didapatkan hasil ibu primipara yang mengalami perdarahan 3 orang (25\%), multipara sebanyak 5 orang $(41,7 \%)$ dan grande multipara 4 orang $(33,3 \%)$.

Hasil uji statistik Chi Square pada tabel 5.6 penelitian ini menunjukkan bahwa uji statistik diterima (H0 ditolak) berarti ada hubungan antara paritas dengan kejadian perdarahan post partum di BPS Ny Niniek Soelasminingsih, S.ST di buktikan dengan hasil uji statistik nilai $\rho$ $0.008 \leq 0.05$ berarti ada hubungan yang positip antara paritas dengan kejadian perdarahan post partum, artinya semakin banyak/sering ibu melahirkan kecenderungan terjadi perdarahan post partum lebih besar .
Berdasarkan hasil diperoleh ibu bersalin yang paling banyak mengalami perdarahan adalah multipara dan grande multipara sebanyak 9 orang $(75 \%)$ hal tersebut sesuai Wiknjosastro, (2002:417) bahwa uterus yang melahirkan banyak anak cenderung bekerja tidak efisien dalam semua kala persalinan, ibu yang sering melahirkan akan ditemui keadaan kesehatan terganggu, anemia, kurang gizi, kekendoran dinding perut dan rahim hal tersebut dapat mengakibatkan gangguan fungsi myometrium untuk kontraksi dan retraksi secara maksimal sehingga tidak dapat menjepit pembuluh darah pada bekas implantasi plasenta sehingga mengakibatkan terjadinya perdarahan post partum.

Selama hamil ibu harus mendapatkan asupan gizi yang cukup untuk pertumbuhan janin dan kesehatan ibu. Kekurangan nutrisi mengakibatkan kecepatan pembentukan $\mathrm{Hb}$ menurun sehingga mengakibatkan anemis. Anemia dalam kehamilan memberikan pengaruh kurang baik bagi ibu pada proses persalinan dan nifas. Anemia dapat menimbulkan penyulit salah satunya perdarahan post partum karena atonia uteri sehingga uterus tidak dapat berkontraksi dengan baik. Kegagalan kontraksi otot rahim menyebabkan pembuluh darah pada bekas implantasi plasenta terbuka sehingga menimbulkan perdarahan

Dari hasil dilapangan bahwa ratarata paritas yang mengalami perdarahan postpartum adalah paritas 4, hal ini karena dengan semakin bertambahnya paritas, maka akan semakin banyak jaringan ikat pada uterus sehingga kemampuan untuk berkontraksi semakin menurun akibatnya sulit melakukan penekanan pada pembuluh-pembuluh darah yang terbuka setelah lepasnya plasenta (Prawirohardjo, 2008 :524).

Penelitian ini menunjukkan bahwa semakin banyak jumlah anak yang dilahirkan akan semakin besar 
kemungkinan terjadinya perdarahan post partum. Selain itu juga akan timbul komplikasi lain yang akan mengakibatkan kematian maternal.

Berdasarkan penelitian yang dilakukan oleh Sulistiawati tahun 2005 yang berjudul "Hubungan Kejadian Perdarahan Post Partum Dini dengan Paritas di RSUP dr. M. Djamil Padang". Menunjukkan hasil pada tahun 2005 bahwa post partum di RSUP dr M Djamil Padang yang mengalami perdarahan adalah $4,40 \%$ dari semua persalinan, sedangkan perdarahan post partum berada di tempat kedua dari sepuluh kasus obstetri terbanyak di RSUP dr M. Djamil Padang.

Penelitian menggunakan analisis bivariat ditemukan bahwa $\mathrm{X}^{2}$ hitung $>X^{2}$ tabel, sehingga dapat menyimpulkan bahwa ada hubungan yang signifikan antara perdarahan postpartum di RSUP dr M. Djamil Padang dengan paritas.

\section{KESIMPULAN}

Dari hasil data pada penelitian dan pembahasan diatas maka dapat ditarik kesimpulan antara lain sebagai berikut:

a. Paritas ibu post partum paling banyak mengalami perdarahan adalah multipara yaitu 5 orang $(41,7 \%)$

b. Ibu post partum di BPS Ny.Niniek Soelasminingsih, S.ST yang tidak mengalami perdarahan sebanyak 49 orang $(80,3 \%)$ dan yang mengalami perdarahan sebanyak 12 orang $(19,7 \%)$, adapun penyebab perdarahan terbanyak adalah atonia uteri sebanyak 6 ibu bersalin $(50 \%)$

c. Setelah dilakukkan uji statistik dengan Chi-Square dengan hasil uji $\rho 0.008$ berati $\rho 0.008 \leq 0.05$ dengan probability $<0.05$ sehingga Ho ditolak dapat disimpulkan "ada hubungan yang positip atau kuat antara paritas dan kejadian perdarahan pada ibu post partum di BPS Ny Niniek Soelasminingsih, S.ST di Desa Klagen Serut Kecamatan Jiwan Kabupaten Madiun".

\section{SARAN}

a. Bagi Tempat Penelitian

Agar penelitian dapat digunakan untuk peningkatan upaya pelayanan kesehatan dalam menyusun intervensi guna pencegahan dan penanggulangan perdarahan post partum.

b. Bagi Profesi

Sebagai salah satu sumber informasi untuk penelitian selanjutnya dan pengembangan profesi kebidanan di masa mendatang.

\section{DAFTAR PUSTAKA}

Bagian Obstetri dan Ginekologi FK Universitas Pajajaran Bandung. 1979. Obstetri Patologi. Bandung: Elstor Offset Bandung.

Berita Jatim. 2011. April Biaya Persalinan Gratis. (On.Line). (http.www.harianbhirawa.co.id/public /2755. Di akses 29 oktober jam 18.06 wib.)

Departemen Pendidikan dan Kebudayaan. 2005. Kamus Besar Bahasa Indonesia. Jakarta: Balai Pustaka

Fajar, dkk. 2009, Statistik untuk praktisi Kesehatan.Yogjakarta: Graha Ilmu.

Kementrian Kesehatan Republik Indonesia. 2011. Jangan Tunda Penurunan AKI dan AKB. (On Line). (http://depkes.go.id/indek.php/berita/p ress-release/1749 diakses tanggal 20 Oktober 2012 jam 18.24 wib).

Manuaba, I. B. G. 1998. Ilmu Kebidanan Penyakit Kandungan dan KB Untuk Pendidikan Bidan.Jakarta : EGC 2004. Penuntun Kepanitraan

Klinik Obstetri Dan Ginekologi. Jakarta: EGC 2008. Ilmu Kebidanan Penyakit Kandungan dan KB Untuk Pendidikan Bidan. Jakarta: EGC

Moochtar, R. (Ed) 1998. Sinopsis Obstetri Fisiologi Patologi. Jakarta: EGC

Nursalam. 2003. Konsep dan Penerapan Metodologi Penelitian Ilmu Keperawatan. Jakarta: Salemba Medika

2008. Konsep dan Penerapan Metodologi Penelitian Ilmu Keperawatan , Edisi Ke 2.Jakarta: Salemba Medika 
Notoatmodjo, S. 2002. Metodologi Penelitian Kesehatan. Jakarta. Rineka Cipta

Prawirohardjo, S. 2008. Ilmu Kebidanan. Jakarta: Yayasan Bina Pustaka Sarwono Prawirohardjo.

Sulistiawati, 2005. Hubungan kejadian perdarahan post partum dini dengan paritas di RSUP dr. M. Djamil Padang. (On Line). (http://www.scrubd.com/doc/9512161 diakses 08 Januari 2013 jam 08.46wib)

Suparwanto. $2010 . \quad$ Konsep Paritas/Partus, (Online), (http://drsuparyanyo.blokspot.com/2010/konse p-paritas-partus,html, diakses 27 Agustus 2012 jam $21.00 \mathrm{wib}$ )

Wiknjosastro, H. Saifudin, A, B. Rochimhadli. (Eds). 1996. Ilmu Bedah Kebidanan. Jakarta: YBP Sarwono Prawirohardjo

Nasional Pelayanan Kesehatan
Maternal Dan Neonatal.Jakarta :
JNPKKR-POGI
2002. Ilmu Kebidanan. Edisi,
$\mathrm{Ke}$ 4. Jakarta: Yayasan Bina Pustaka Sarwono Prawirohardjo: EGC 